\title{
Pressure-temperature phase diagram of the dimorphism of the anti- inflammatory drug nimesulide
}

\author{
M. Barrio ${ }^{1}$, J. Huguet ${ }^{1}$, B. Robert ${ }^{2}$, I. B. Rietveld ${ }^{3,4, *}$, R. Céolin ${ }^{1,5}$, J.L1. Tamarit ${ }^{1}$
}

${ }^{1}$ Departament de Física, ETSEIB, Universitat Politècnica de Catalunya, Diagonal 647, 08028 Barcelona, Catalonia, Spain

2 Sanofi R\&D, Pharmaceutics Development Platform/Analytical Sciences/Solid State group, 13 quai Jules Guesde, F-94400 Vitry sur Seine, France

${ }^{3}$ Normandie Université, Laboratoire SMS-EA3233, Université de Rouen, F76821, Mont Saint Aignan, France

${ }^{4}$ Laboratoire de Chimie Physique, Faculté de Pharmacie, Université Paris Descartes, USPC, 4 avenue de l'Observatoire, 75006 Paris, France

${ }^{5}$ LETIAM, EA7357, IUT Orsay, Université Paris Sud, rue Noetzlin, 91405 Orsay, France

* Corresponding author: ivo-boudewijn.rietveld@univ-rouen.fr 


\begin{abstract}
Understanding the phase behavior of active pharmaceutical ingredients is important for formulations of dosage forms and regulatory reasons. Nimesulide is an anti-inflammatory drug that is known to exhibit dimorphism. It is shown in the paper that form II is intrinsically monotropic in relation to form I. This result has been obtained by experimental means, involving high-pressure measurements. In addition, it has been shown that with very limited means and statistical melting data, the same conclusion can be obtained, demonstrating that in first instance topological high-pressure phase diagrams can be obtained without measuring any high-pressure data.
\end{abstract}

\title{
Keywords:
}

Polymorphism, thermodynamics, pressure-temperature phase diagram, phase behavior, crystallography, calorimetry, preformulation 


\section{Introduction}

Nimesulide, a drug with non-steroidal anti-inflammatory (NSAID) properties, is only sparsely used in therapeutics, because cases of serious hepatotoxicity have been observed. Its molecular structure can be seen in Figure 1. The active pharmaceutical ingredient (API) has two known polymorphs and, for both, structural and calorimetric data are available in the literature. One crystal structure at $293 \mathrm{~K}$ had in first instance been solved by Dupont et al. in 1995. ${ }^{1}$ The structure was later ascribed to form II. In 2011, Sanphui et al. solved the structure of a second polymorph and redetermined the one of form II, both at $100 \mathrm{~K}^{2}$ The crystallographic data in Table 1 are in accordance with those compiled by Sanphui et $\mathrm{al}^{2}$ and provided for reference as the data will be used in this article.

Nimesulide polymorphism has been investigated using X-ray powder diffraction and DSC by Bergese et al. ${ }^{3}$ In Figure 1 of this reference, ${ }^{3}$ X-ray patterns for various nimesulide samples have been provided: native nimesulide (NN), supplied by Helsimm-CH, and polymorphic nimesulide (PN), i.e. a physical mixture of two polymorphs with a $\mathrm{I} / \mathrm{II}$ polymorph ratio of 0.69 . The two patterns have been compared to a calculated pattern $(\mathrm{CN})$ using data from reference 1 . Although no refinement of the lattice parameters was carried out for form II which would have provided the specific volumes of the polymorph, Bergese et al carried out DSC studies and reported values for the melting enthalpies of forms I and II, which have been compiled in Table 2 of the present paper.

A few years later, Di Martino et al. obtained the same two polymorphs as Bergese et al. and they demonstrated that mixtures of forms I and II obtained from ethanol consist of fine needles. ${ }^{4}$ They performed differential scanning calorimetry (DSC) measurements at various heating rates from 0.5 to $40 \mathrm{~K} \mathrm{~min}^{-1}$ of which the results appear to indicate that the melting temperature of form II is heating-rate dependent (although the range is rather small from $418.9 \mathrm{~K}$ to the melting temperature of form I at $420.6 \mathrm{~K}$ ), while the melting of form I occurs at constant temperature. ${ }^{4}$ In addition, at heating rates below $1 \mathrm{~K} \mathrm{~min}^{-1}$, it can be observed that the melting of form II is followed by recrystallization into form I. ${ }^{4}$ Unfortunately, no value of the melting enthalpy of form II was reported by the authors. Moneghini et al. obtained both polymorphs too and reported on it in the same year as Di Martino. Again, they only mentioned the melting enthalpy of form I (see Table 2). ${ }^{5}$

In 2011, Sanphui et al. obtained DSC curves from forms I and II similar to those of Bergese et al. for form I and to those of Di Martino et al. for form II at $5 \mathrm{~K} \mathrm{~min}^{-1}$ rate..$^{2-4}$ Sanphui et al. concluded that the two forms have an enantiotropic relationship, from data 
indicating that form II melts at $140^{\circ} \mathrm{C}$ and recrystallizes into form I, which subsequently melts at around $147{ }^{\circ} \mathrm{C} .{ }^{2}$ Because melting and recrystallization is certainly not evidence of an enantiotropic relationship between the two polymorphs, the dimorphism of nimesulide and its thermodynamic characteristics has been re-investigated. The experimental data has been subsequently used to construct a topological pressure-temperature phase diagram to have a full understanding of the polymorphic behavior of nimesulide and to avoid uncontrolled transformations while processing the API under increased pressure and/or temperature.

\section{Materials and methods}

Nimesulide was purchased from Sigma Aldrich (Madrid, Spain). A part of the sample was analyzed as such and another part was dissolved in various solvents yielding, after evaporation at room temperature, either form I (ethanol), form II (acetonitrile) or mixtures of the two forms (acetone).

High-resolution X-ray powder diffraction data were recorded by means of a horizontally mounted INEL cylindrical position-sensitive detector (CPS-120) using DebyeScherrer geometry (angular step ca. $0.029^{\circ} 2 \theta$ over a $2 \theta$-range from 2 to $115^{\circ}$ ) and monochromatic $\mathrm{Cu} \mathrm{K \alpha} \alpha_{1}(\lambda=1.5406 \AA)$ radiation $(40 \mathrm{kV}$ and $25 \mathrm{~mA})$. The temperature of the sample was set by means of a liquid nitrogen 700 series Cryostream Cooler from Oxford Cryosystems with an accuracy of $0.1 \mathrm{~K}$. Samples were placed into 0.5 -mm-diameter Lindemann capillaries, which were rotating around their axes during data collection to reduce the effects of preferential orientation. Calibration was performed by cubic spline fitting of the diffraction pattern of the cubic phase of $\mathrm{Na}_{2} \mathrm{Ca}_{2} \mathrm{Al}_{2} \mathrm{~F}_{4}$. The peak positions were determined after pseudo-Voigt fitting of the peaks. Patterns were fitted through a pattern matching procedure in the FullProf Suite Package. ${ }^{6,7}$

Differential scanning calorimetry (DSC) experiments were carried out on a Q100 analyzer from TA Instruments (New Castle, DE, USA) with sample masses from 10 to $20 \mathrm{mg}$ and heating rates from 1 up to $10 \mathrm{~K} \mathrm{~min}^{-1}$. The measurements were carried out on samples sealed in aluminum pans.

A high-pressure differential thermal analyzer (HP-DTA) was used to study the melting behavior in the pressure range from $0 \mathrm{MPa}$ to $250 \mathrm{MPa}$. The HP-DTA was an in-house constructed apparatus similar to that designed by Würflinger. ${ }^{8}$ Samples were sealed in cylindrical tin pans and to ensure that the pans did not contain any residual air, specimens were mixed with an inert perfluorinated liquid (Galden ${ }^{\circledR}$ from Bioblock Scientifics, Illkirch, 
France) before sealing. HP-DTA scans were carried out with a heating rate of $2 \mathrm{~K} \mathrm{~min}^{-1}$. DSC runs at ordinary pressure with mixtures of nimesulide and perfluorinated liquid were carried out to verify that the mixture showed no interaction.

Isothermal vapor pressure measurements were conducted in the temperature range from 368-423 K for form I and 368-413 K for form II by means of a DVS Vacuum system from Surface Measurements Systems (London, United Kingdom). Measurements are carried out in a Knudsen cell with an orifice diameter of $241 \mu \mathrm{m}$, as determined by scanning electron microscopy.

\section{Results}

Lattice parameters were determined as a function of temperature by means of X-ray powder diffraction measurements (see Figure 2). The results confirm that the purchased powder was the orthorhombic form I (see Figure 2a). Evaporation of nimesulide in ethanol and acetone gave rise to a mixture of forms I and II, whereas evaporation of solutions in acetonitrile provided crystals of form II as demonstrated by the diffraction pattern in figure $2 b$.

The specific volumes obtained from the X-ray powder diffraction patterns have been plotted as a function of temperature in Figure 3 and were both fitted with a second order polynomial, because a slight curvature can be observed:

$v_{\mathrm{I}} / \mathrm{cm}^{3} \mathrm{~g}^{-1}=0.6466( \pm 0.0011)+7.3( \pm 0.9) \times 10^{-6} \mathrm{~T} / \mathrm{K}+1.03( \pm 0.17) \times 10^{-7} T^{2} / \mathrm{K}^{2}\left(\mathrm{R}^{2}=0.999\right)$

$v_{\text {II }} / \mathrm{cm}^{3} \mathrm{~g}^{-1}=0.6487( \pm 0.0011)+5.8( \pm 0.9) \times 10^{-6} \mathrm{~T} / \mathrm{K}+1.43( \pm 0.17) \times 10^{-7} T^{2} / \mathrm{K}^{2}\left(\mathrm{R}^{2}=0.999\right)$

(2)

DSC measurements at ordinary pressure (Figure 4) of the as-received sample confirm the melting process corresponding to form I (peak a1 in Figure 3). On cooling from the molten state, two slightly different behaviors have been observed, either the liquid crystallizes into form I on cooling as demonstrated by the subsequent heating, which leads to the melting of form I, or the liquid becomes a glass. In the latter case, subsequent heating shows the glass transition at ca. $292 \mathrm{~K}$ (inset in Figure 4), the recrystallization of the liquid into form I (peak b1 in Figure 3) and, finally, the melting of form I (peak b2 in Figure 4). Form II, obtained by 
slow evaporation of acetonitrile, shows a melting peak in its DSC curve (peak c1 in Figure 4) concomitantly followed by recrystallization into form I (peak c2 in Figure 4) and, finally the melting of form I (peak c3 in Figure 4). Mean values for the melting temperatures and enthalpy changes related to the phase transitions have been reported in Table 2.

High-pressure thermal analysis measurements were carried out for form I as well as for form II. The same behavior described for DSC measurements at ordinary pressure were observed for the entire analyzed pressure range. The high-pressure melting temperatures of both forms as a function of the pressure are shown in Figure 5. The experimental melting pressures as a function of temperature were fitted with a linear expression leading to:

$$
\begin{aligned}
& P_{\mathrm{I}-\mathrm{L}} / \mathrm{MPa}=3.843( \pm 0.036) \cdot T / \mathrm{K}-1623( \pm 16) \\
& P_{\mathrm{II}-\mathrm{L}} / \mathrm{MPa}=4.024( \pm 0.073) \cdot T / \mathrm{K}-1692( \pm 33)
\end{aligned}
$$

The natural logarithm of the vapor pressure points of forms I and II as a function of the reciprocal of the temperature, 1000/T, have been plotted in the inset of Figure 5 . As expected, the vapor pressure of the stable form I is lower than that of the metastable form II for the temperature range studied. Using the expression $\ln P=B-\Delta_{\text {sub }} H / R T$, with $R$ the gas constant (8.3145 $\left.\mathrm{J} \mathrm{mol}^{-1} \mathrm{~K}^{-1}\right)$ and $B$ a fitting parameter, the sublimation enthalpy, $\Delta_{\text {sub }} H$, can be obtained:

$$
\begin{aligned}
& \ln \left(P_{\text {I-vap }} / \mathrm{Pa}\right)=54.2( \pm 0.8)-22045( \pm 315) \cdot 1 /(T / \mathrm{K}) \\
& \ln \left(P_{\text {II-vap }} / \mathrm{Pa}\right)=53.3( \pm 2.2)-21644( \pm 356) \cdot 1 /(T / \mathrm{K})
\end{aligned}
$$

The sublimation enthalpies can be calculated by multiplying the $\Delta_{\text {sub }} H / R$ values of the equations (5) and (6) by $R: \Delta_{\text {sub,I }} H=183.3 \pm 2.6 \mathrm{~kJ} \mathrm{~mol}^{-1}\left(594.5 \pm 8.5 \mathrm{~J} \mathrm{~g}^{-1}\right)$ and $\Delta_{\text {sub,II }} H=$ $180.0 \pm 3.0 \mathrm{~kJ} \mathrm{~mol}^{-1}\left(584 \pm 10 \mathrm{~J} \mathrm{~g}^{-1}\right)$.

It can be observed in Figure 5 that the two-phase equilibrium lines I-L and II-L diverge with increasing pressure and the two-phase equilibria I-vap and II-vap converge with increasing temperature.

\section{Discussion}

The temperature of the I-II transition has not been observed experimentally by conventional DSC; however, with the two vapor pressure expressions, the triple point, where 
forms I and II, and the vapor are in equilibrium can be calculated. Setting equations 5 and 6 equal to each other, leads to the triple point temperature, $T_{\mathrm{I}-\mathrm{II}-\mathrm{V}}$, of $446 \mathrm{~K}$. With either expression, it can be calculated that the vapor pressure of solid nimesulide at that temperature would be $112 \mathrm{~Pa}$. The solid-solid transition temperature is higher than the melting temperatures of the two solid phases leading to the conclusion that the two forms possess a monotropic relationship.

Although the heat of transition from form I to form II has not been obtained experimentally, it can be calculated with the melting enthalpies leading to $\Delta_{\mathrm{I} \rightarrow \mathrm{II}} H=\Delta_{\mathrm{I} \rightarrow \mathrm{L}} H-$ $\Delta_{\mathrm{II} \rightarrow \mathrm{L}} H=8.9 \mathrm{~J} \mathrm{~g}^{-1}$, while neglecting the contributions of the specific heats in the interval of 2.5 degrees between the two melting temperatures. Because the transition $\mathrm{I} \rightarrow \mathrm{II}$ is found to be endothermic, the Le Chatelier principle implies that the transition is favored by an increase of temperature; thus at the calculated transition temperature of $446 \mathrm{~K}$, form I should spontaneously transform into form II. Using the sublimation enthalpies from eqs. 5 and 6 , the enthalpy difference between the two solid phases can be calculated independently of the melting enthalpies, which leads to $10.8 \mathrm{~J} \mathrm{~g}^{-1}$ for $\Delta_{\mathrm{I} \rightarrow \mathrm{II}} H$, which is relatively close to the value found with the melting enthalpies.

Because the experimental P-T melting curves diverge on increasing the pressure, the two equilibria should cross at negative pressure. At the intersection, forms I and II and the liquid are in equilibrium and this is therefore the triple point I-II-L, marked by $\mathrm{O}_{4}$ in Figure 6. The coordinates can be calculated by setting the two equations 3 and 4 equal to each other. This results in $T_{\text {I-II-L }}=381 \mathrm{~K}, P_{\text {I-II-L }}=-158 \mathrm{MPa}$.

The equilibrium between the two solid phases I and II must pass through triple points I-II-V and I-II-L. Triple point I-II-V was calculated to be $T_{\mathrm{I}-\mathrm{II}-\mathrm{V}}=446 \mathrm{~K}$ and $P_{\mathrm{I}-\mathrm{II}-\mathrm{V}}=112 \mathrm{~Pa}$. If the solid-solid equilibrium is approximated by a straight line, which is generally true over a considerable pressure and temperature range, ${ }^{9-12}$ the equation for the I-II equilibrium becomes:

$P_{\mathrm{I}-\mathrm{II}} / \mathrm{MPa}=2.46 T / \mathrm{K}-1094$

It can be seen that the hierarchy of the phase equilibrium slopes follows $\mathrm{d} P / \mathrm{d} T_{\text {II-L }}>$ $\mathrm{d} P / \mathrm{d} T_{\text {I-L }}>\mathrm{d} P / \mathrm{d} T_{\text {I-II }}$, respectively from the eqs. 4,3 , and 8 . With the position of the I-II-L triple point at negative pressure, the given hierarchy of the slopes leads necessarily to a monotropic system as can be seen in the pressure-temperature phase diagram in Figure 6. 
Overall monotropy is the last of the four possible phase diagrams for dimorphic systems described by Bakhuis-Roozeboom. ${ }^{13}$ In this case, form II does not possess a stable phase region in the phase diagram, because it will always be metastable against form I, the liquid, and the vapor phase. Other examples of monotropic APIs are biclotymol, ${ }^{14}$ rimonabant, ${ }^{15}$ triethylenetetramine hydrochloride ${ }^{16,17}$ and rotigotine. ${ }^{18}$

One could argue that this case of polymorphism was resolved because of the availability of vapor pressure data. This is indeed true, as experimental proof is always better than approximations even if they are based on thermodynamics or on statistical information. However, even without the vapor pressure data, the same topological phase diagram will be obtained, even if some of the phase equilibria will have a slightly different position. First of all, if the solid-solid transition temperature cannot be calculated from vapor pressure data, the following formula can be used, which is based on thermodynamics, although in the present case the heat capacity differences are neglected (because they are not known for this system): ${ }^{19}$

$$
T_{I \rightarrow I I}=\frac{\Delta_{I \rightarrow L} H-\Delta_{I I \rightarrow L} H}{\frac{\Delta_{I \rightarrow L} H}{T_{I \rightarrow L}}-\frac{\Delta_{I I \rightarrow L} H}{T_{I I \rightarrow L}}}
$$

With eq. 9 a transition temperature of $457 \mathrm{~K}$ is found, which is 11 degrees higher than with the vapor pressure curves. The deviation might be caused by the absence of the heat capacities in eq. 9; however, inaccuracies in the data cannot be ruled out either. The vapor pressure of nimesulide was calculated to be $112 \mathrm{~Pa}$ at the solid-solid transition temperature. Considering the slope of the solid-solid phase equilibrium of $2.46 \mathrm{MPa} \mathrm{K}^{-1}$, in terms of megapascal $112 \mathrm{~Pa}$ equals $0.000112 \mathrm{MPa}$ and can therefore safely be "approximated" by $0 \mathrm{MPa}$. Often, vapor pressures of APIs are even smaller. Thus the I-II-V triple point $\left(\mathrm{O}_{2}\right.$ in Figure 6$)$ can be given as $457 \mathrm{~K}, 0 \mathrm{MPa}$. Using the I-II-L triple point obtained by high-pressure calorimetry $381 \mathrm{~K}$, $-158 \mathrm{MPa}$, the I-II equilibrium would be:

$P_{\mathrm{I}-\mathrm{II}} / \mathrm{MPa}=2.09 T / \mathrm{K}-953$

It can be seen that this slope is somewhat more gradual than the slope in eq. 8 , but the hierarchy of the phase equilibria $\mathrm{d} P / \mathrm{d} T_{\text {II-L }}>\mathrm{d} P / \mathrm{d} T_{\text {I-L }}>\mathrm{d} P / \mathrm{d} T_{\text {I-II }}$ remains the same and so does therefore the conclusion that form II is monotropic. 
This approach can be taken one step further, if the melting data as a function of pressure and temperature is replaced by an approach involving the Clapeyron equation. Instead of the measured curves, the slopes of the melting equilibria can be calculated using experimental data of the system in combination with statistical data for small organic molecules including APIs. As the Clapeyron equation provides the slope of an equilibrium with the differences in the entropy and the volumes of the two phases involved, $\mathrm{d} P / \mathrm{d} T=$ $\Delta s / \Delta v=\Delta h /(T \Delta v)$, these quantities need to be determined at the equilibrium temperature.

For the melting equilibrium of form I, which occurs at $422.4 \mathrm{~K}$, the specific volume of form I, $v_{\mathrm{I}}$, equals $0.6681 \mathrm{~cm}^{3} \mathrm{~g}^{-1}$. It is found that for the highest melting polymorph, the volume change on melting is on average $11 \%$ for small molecules, ${ }^{20-22}$ which leads to a $\Delta_{\mathrm{I} \rightarrow \mathrm{L}} v$ of $0.0735 \mathrm{~cm}^{3} \mathrm{~g}^{-1}$ and the liquid would have a specific volume at that point of $0.7415 \mathrm{~cm}^{3} \mathrm{~g}^{-1}$. Using the melting data obtained in this work and listed in Table 2 together with the volume change on melting of form I, the slope for the I-L equilibrium is found to be $3.79 \mathrm{MPa} \mathrm{K}^{-1}$, which is very close to the experimental value obtained by the high pressure DTA measurements of $3.84 \mathrm{MPa} \mathrm{K}^{-1}$. As the experimental slope is known, the calculation can also be inverted to calculate the volume change on melting, which leads to $0.0724 \mathrm{~cm}^{3} \mathrm{~g}^{-1}$. In that case, the volume of the liquid on melting would be $v_{\mathrm{I}}+\Delta_{\mathrm{I} \rightarrow \mathrm{L}} v=v_{\mathrm{L}}=0.7404 \mathrm{~cm}^{3} \mathrm{~g}^{-1}$ and the ratio $v_{\mathrm{L}} / v_{\mathrm{I}}$ at melting becomes 1.108 , i.e. virtually the same as the mean value of 1.11 .

To calculate the slope of the melting equilibrium of form II, the volume of the liquid needs to be known at its melting point. For small molecular APIs, a mean liquid expansion coefficient, $\alpha_{\mathrm{L}}$ based on the equation $v_{\mathrm{L}}(T)=v_{0}\left(1+\alpha_{\mathrm{L}} T\right)$ with $v_{0}$ the volume of the liquid at the intercept $T=0 \mathrm{~K}$, has been found to be $1.25 \times 10^{-3} \mathrm{~K}^{-1} \cdot{ }^{20,21}$ With this value for the expansion coefficient, the specific volume of the liquid as a function of temperature can be written as $v_{\mathrm{L}}(T)=0.4846\left(1+1.25 \times 10^{-3} T\right)$, using the known specific volume of the melt at the melting point of form I. The specific volume of the melt at $T_{\mathrm{II}-\mathrm{L}}=419.8 \mathrm{~K}$ becomes $0.7389 \mathrm{~cm}^{3} \mathrm{~g}^{-1}$. For the specific volume of form II at the same temperature, one obtains $0.6763 \mathrm{~cm}^{3} \mathrm{~g}^{-1}$, which leads to the change in specific volume, $\Delta_{\mathrm{II} \rightarrow \mathrm{L}} v$, of $0.0625 \mathrm{~cm}^{3} \mathrm{~g}^{-1}$. With the Clapeyron equation, this leads to the slope for the melting equilibrium of form II of $\mathrm{d} P / \mathrm{d} T_{\mathrm{II-L}}=4.14 \mathrm{MPa} \mathrm{K}^{-1}$ (close to the experimental slope of $4.024 \mathrm{MPa} \mathrm{K}^{-1}$ ).

This result demonstrates that even relying entirely on extrapolated and statistical data, the same type of phase diagram will be found, making it possible to draw conclusions on the stability of solid forms and produce relevant topological phase diagrams for formulation decisions in the pharmaceutical industry just using standard laboratory equipment and without 
having to resort to pressure measurements, either in the form of high pressure or in the form of vapor pressure.

\section{Conclusions}

Pressure and temperature dependence of melting and sublimation curves have been obtained for nimesulide forms I and II. It can be unambiguously concluded that form II is overall monotropic in relation to form I. The phase diagram belongs to the fourth case of four possible types of phase diagrams listed by Bakhuis-Roozeboom for systems with crystalline dimorphism. ${ }^{13,23}$ Although the other cases were based on examples known to him, for the phase diagram of overall monotropy, he did not provide an existing example. As mentioned above, the APIs biclotymol, rotigotine, rimonabant, and triethylenetetramine hydrochloride were recently found to be overall monotropic dimorphic systems. ${ }^{14-16,18}$ In addition, the organic molecules 2,2-dichloropropane and tetrachloromethane were found to exhibit overall monotropy. 24,25

\section{Acknowledgements}

This work has been supported by the Spanish Ministry of Science and Innovation through the project FIS2014-54734-P and by the Generalitat de Catalunya under the project 2014 SGR$581)$.

\section{Conflict of Interest Statement}

The authors declare no conflict of interest. B.R. is employee of Sanofi.

\section{References}

1. Dupont L, Pirrotte B, Masereel B, Delarge J, Geczy J 1995. Nimesulide. Acta Crystallogr C 51:507-509.

2. Sanphui P, Sarma B, Nangia A 2011. Phase transformation in conformational polymorphs of nimesulide. J Pharm Sci 100(6):2287-2299.

3. Bergese P, Bontempi E, Colombo I, Gervasoni D, Depero LE 2003. Microstructural investigation of nimesulide-crospovidone composites by X-ray diffraction and thermal analysis. Compos Sci Technol 63:1197-1201.

4. Di Martino P, Censi R, Barthelemy C, Gobetto R, Joiris E, Masic A, Odou P, Martelli $S$ 2007. Characterization and compaction behaviour of nimesulide crystal forms. Int J Pharm 342(1-2):137-144. 
5. Moneghini M, Perissutti B, Vecchione F, Kikic I, Cortesi A, Princivalle F 2007. Supercritical antisolvent precipitation of nimesulide: preliminary experiments. Current Drug Delivery 4:241-248.

6. Rodriguez-Carvajal J 1993. Recent advances in magnetic structure determination by neutron powder diffraction. Physica B 192:55-69.

7. Rodriguez-Carvajal J, Roisnel T, Gonzales-Platas J. 2005. Full-Prof suite version 2005. Laboratoire Léon Brillouin, CEA-CNRS, CEN Saclay, France.

8. Würflinger A 1975. Differential thermal-analysis under high-pressure IV. Lowtemperature DTA of solid-solid and solid-liquid transitions of several hydrocarbons up to 3 kbar. Ber Bunsen-Ges Phys Chem 79(12):1195-1201.

9. Gana I, Barrio M, Do B, Tamarit J-L, Céolin R, Rietveld IB 2013. Benzocaine polymorphism: Pressure-temperature phase diagram involving forms II and III. Int J Pharm 456(2):480-488.

10. Gana I, Barrio M, Ghaddar C, Nicolai B, Do B, Tamarit JL, Safta F, Rietveld IB 2015. An integrated view of the influence of temperature, pressure, and humidity on the stability of trimorphic cysteamine hydrochloride. Mol Pharmaceut 12:2276-2288. 11. Rietveld I, Barrio M, Espeau P, Tamarit J, Céolin R 2011. Topological and Experimental Approach to the Pressure-Temperature-Composition Phase Diagram of the Binary Enantiomer System d- and l-Camphor. J Phys Chem B 115(7):1672-1678. 12. Toscani S, Céolin R, Ter Minassian L, Barrio M, Veglio N, Tamarit J-L, Louër D, Rietveld IB 2016. Stability hierarchy between piracetam forms I, II, and III from experimental pressure-temperature diagrams and topological inferences. Int J Pharm 497:96-105.

13. Bakhuis Roozeboom HW. 1901. Die heterogenen Gleichgewichte vom Standpunkte der Phasenlehre. Erstes Heft: Die Phasenlehre - Systeme aus einer Komponente., Braunschweig: Friedrich Vieweg und Sohn.

14. Céolin R, Tamarit JL, Barrio M, Lopez DO, Nicolaï B, Veglio N, Perrin MA, Espeau P 2008. Overall monotropic behavior of a metastable phase of biclotymol, 2,2'methylenebis(4-chloro-3-methyl-isopropylphenol), inferred from experimental and topological construction of the related P-T state diagram. J Pharm Sci 97(9):3927-3941. 15. Perrin M-A, Bauer M, Barrio M, Tamarit J-L, Céolin R, Rietveld IB 2013. Rimonabant dimorphism and its pressure-temperature phase diagram: A delicate case of overall monotropic behavior. J Pharm Sci 102(7):2311-2321.

16. Henriet T, Gana I, Ghaddar C, Barrio M, Cartigny Y, Yagoubi N, Do B, Tamarit JL, Rietveld IB 2016. Solid state stability and solubility of triethylenetetramine hydrochloride. Int J Pharm 511:312-321.

17. Henriet T, Nicolaï B, Ghaddar C, Barrio M, Do B, Yagoubi N, Tamarit J-L, Rietveld IB 2015. Triethylenetetramine dihydrochloride: Interactions and Conformations in two Anhydrous Structures and a Hydrate. Cryst Growth Des 15(1):348-357.

18. Rietveld IB, Céolin R 2015. Rotigotine: unexpected polymorphism with predictable overall monotropic behavior. J Pharm Sci 104(12):4117-4122.

19. Yu L 1995. Inferring Thermodynamic Stability Relationship of Polymorphs from Melting Data. J Pharm Sci 84(8):966-974.

20. Rietveld IB, Céolin R 2015. Phenomenology of crystalline polymorphism: overal monotropic behavior of the cardiotonic agent FK664 forms A and B. J Therm Anal Calorim 120(2):1079-1087.

21. Céolin R, Rietveld IB 2015. The topological pressure-temperature phase diagram of ritonavir, an extraordinary case of crystalline dimorphism. Ann Pharm Fr 73(1):2230. 
22. Goodman BT, Wilding WV, Oscarson JL, Rowley RL 2004. A note on the relationship between organic solid density and liquid density at the triple point. J Chem Eng Data 49(6):1512-1514.

23. Céolin R, Rietveld IB 2016. X-ray crystallography, an essential tool for the determination of thermodynamic relationships between crystalline polymorphs. Ann Pharm Fr 74:12-20.

24. Negrier P, Pardo LC, Salud J, Tamarit JL, Barrio M, Lopez DO, Wurflinger A, Mondieig D 2002. Polymorphism of 2,2-dichloropropane: Crystallographic characterization of the ordered and disordered phases. Chem Mater 14(5):1921-1929. 25. Tamarit JL, Barrio M, Pardo LC, Negrier P, Mondieig D 2008. High-pressure properties inferred from normal-pressure properties. J Phys: Condens Matter 20(24):244110.

\section{Figure Captions}

Figure 1. Chemical structure of nimesulide or 4-nitro-2-phenoxymethanesulfonanilide, $\mathrm{C}_{13} \mathrm{H}_{12} \mathrm{~N}_{2} \mathrm{O}_{5} \mathrm{~S}, \mathrm{M}=308.31 \mathrm{~g} \mathrm{~mol}^{-1}$.

Figure 2. Experimental (points) and fitted (lines) diffraction patterns along with the calculated Bragg peak positions (vertical bars) for (a) the orthorhombic form I and (b) the monoclinic form II of nimesulide.

Figure 3. Specific volume as a function of temperature for form I (solid circles) and form II (open circles). Literature data reported in Table 1 for each form are shown (solid and open squares for forms I and II, respectively).

Figure 4. Differential scanning calorimetry curves obtained by heating for form I (black line), after cooling from the liquid phase (dashed red line) and for form II (blue dotted line) obtained from recrystallization in acetonitrile.

Figure 5. Experimental melting pressures of forms I (solid black circles) and II (open blue circles) as a function of temperature. Inset: Experimental vapor pressures (in logarithmic scale) for forms I and II (symbols as indicated above) as a function of the reciprocal temperature $1000 / T$. 
Figure 6. Topological pressure-temperature phase diagram of the stability hierarchy of the nimesulide polymorphs I and II. The lines represent two-phase equilibria, solid lines: stable, broken lines: metastable, dashed-dotted lines: supermetastable. Solid circle marked by $\mathrm{O}_{1}$ : the stable triple point I-L-V, open circles: metastable triple points with $\mathrm{O}_{2}: \mathrm{I}-\mathrm{II}-\mathrm{V}, \mathrm{O}_{3}: \mathrm{II}-\mathrm{L}-\mathrm{V}$, and $\mathrm{O}_{4}$ : I-II-L.

\section{Tables Captions}

Table 1. Single crystal data of form I and form II of nimesulide

Table 2. Calorimetric data for the two known polymorphs of nimesulide 


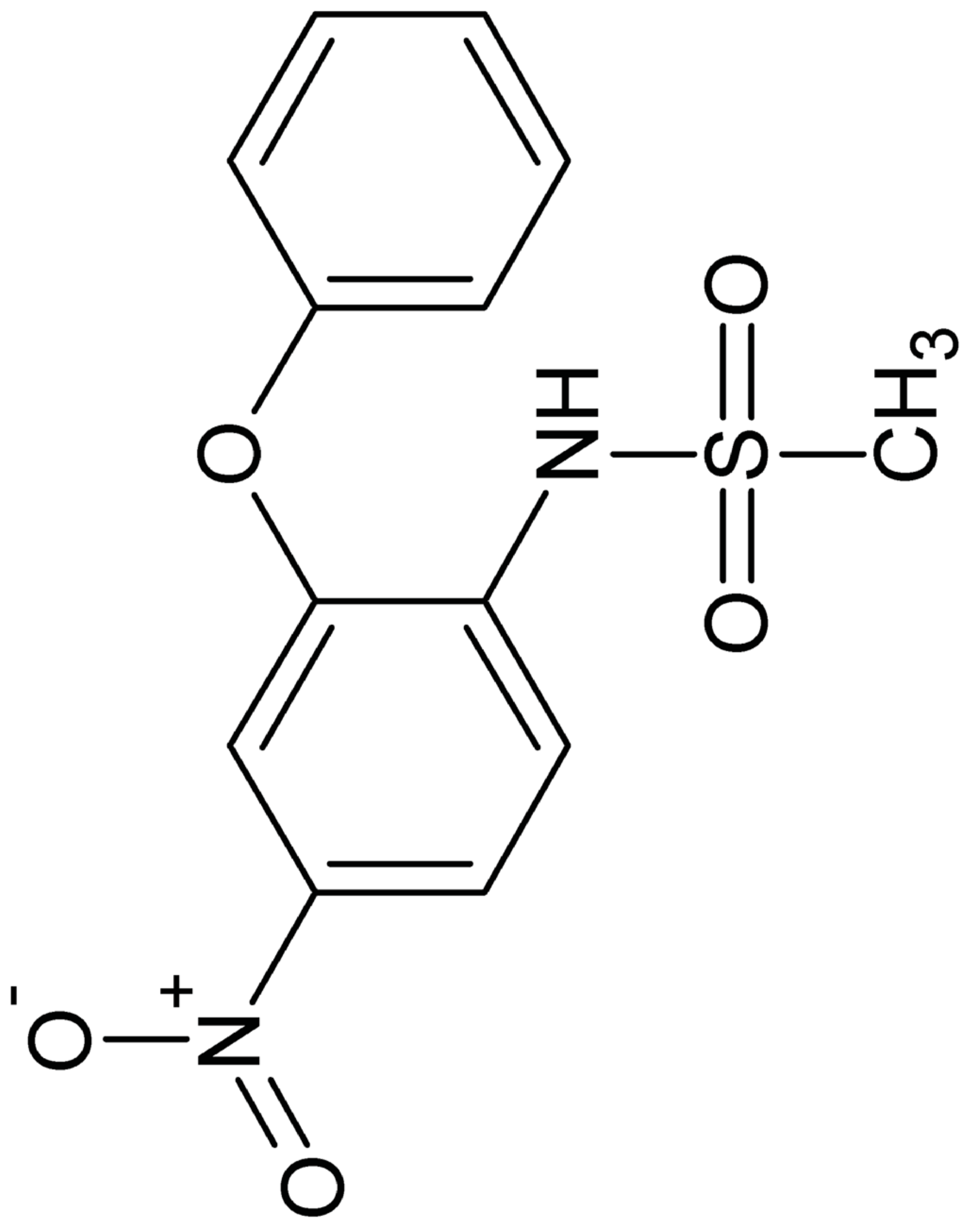



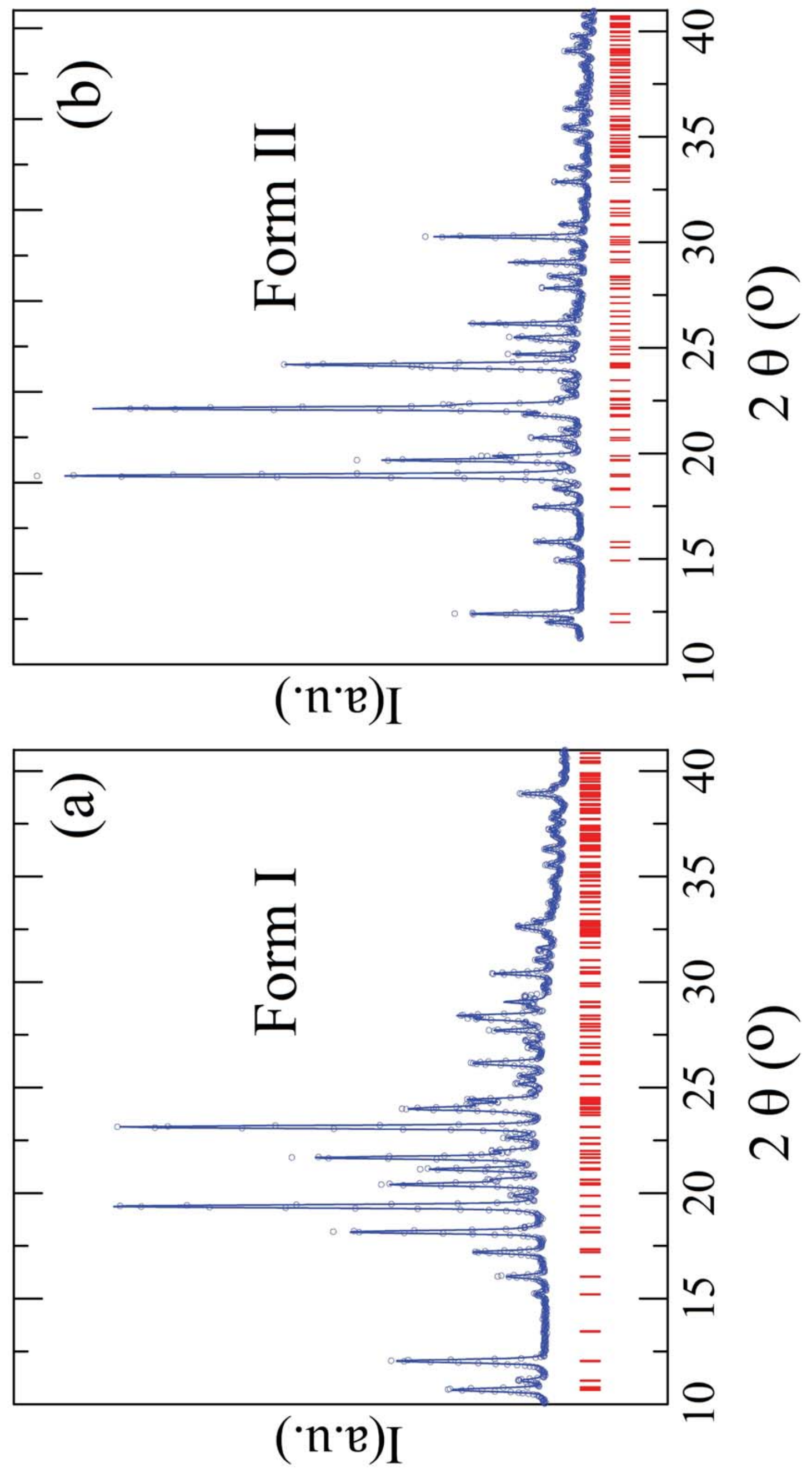


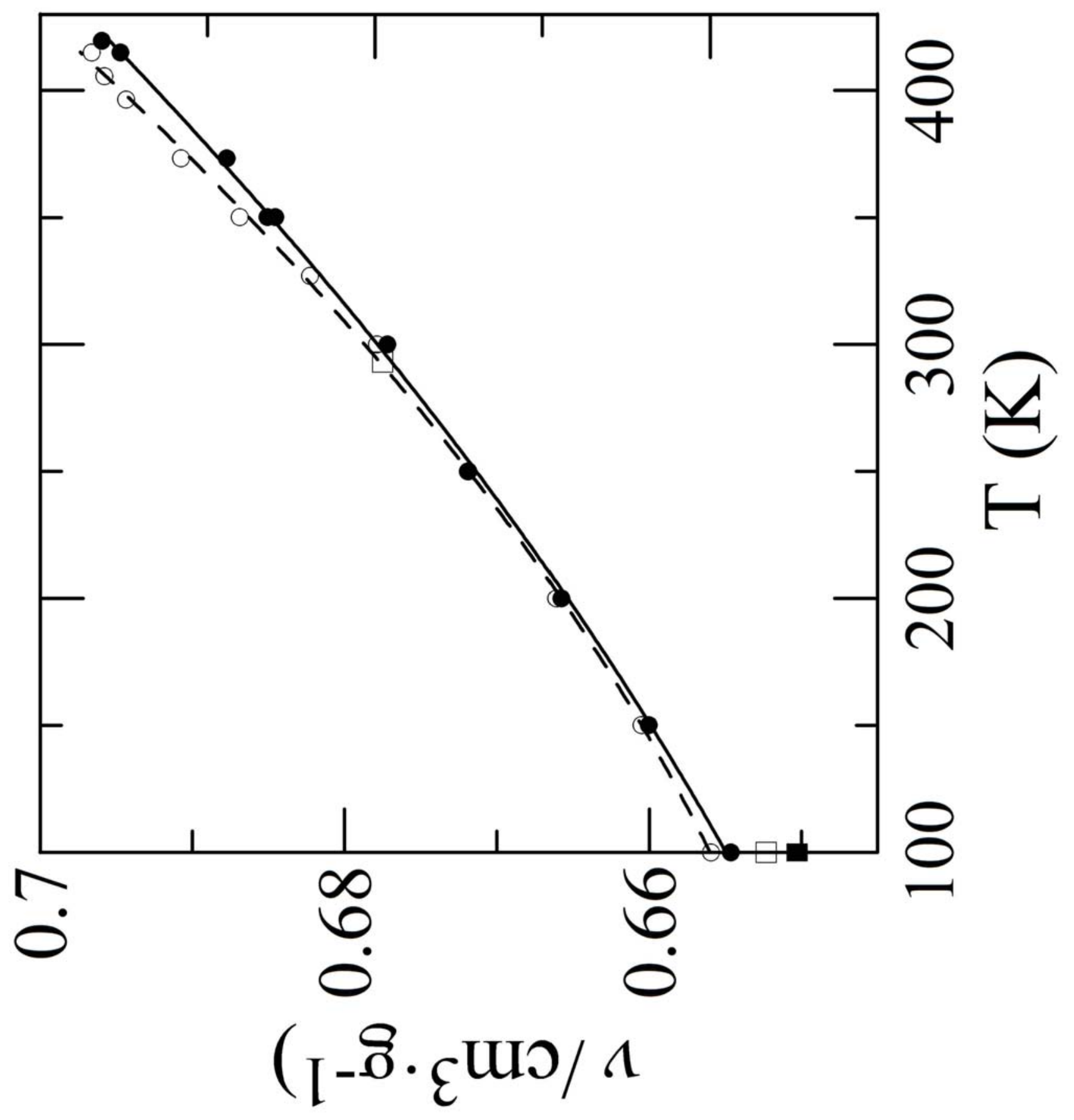




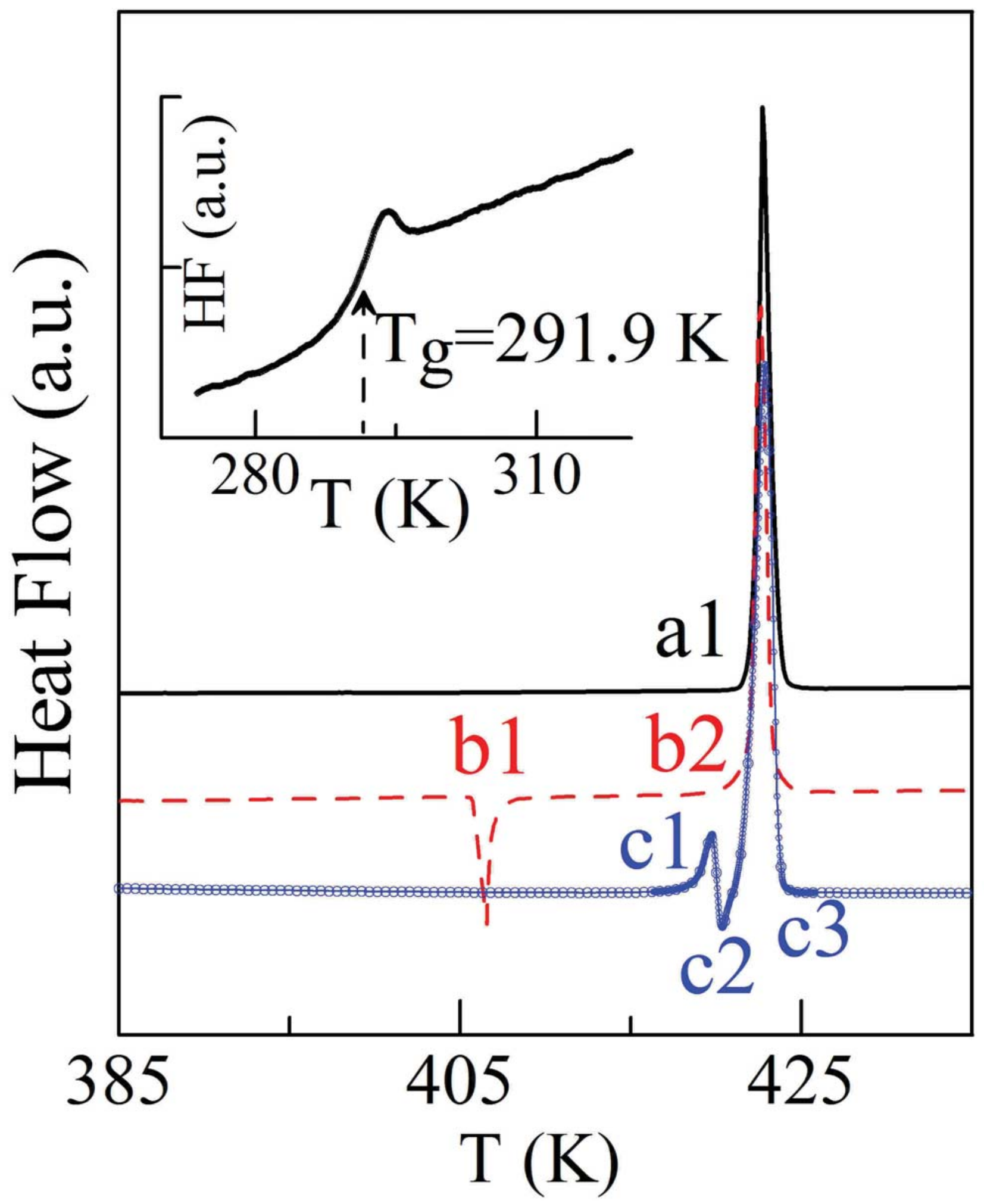




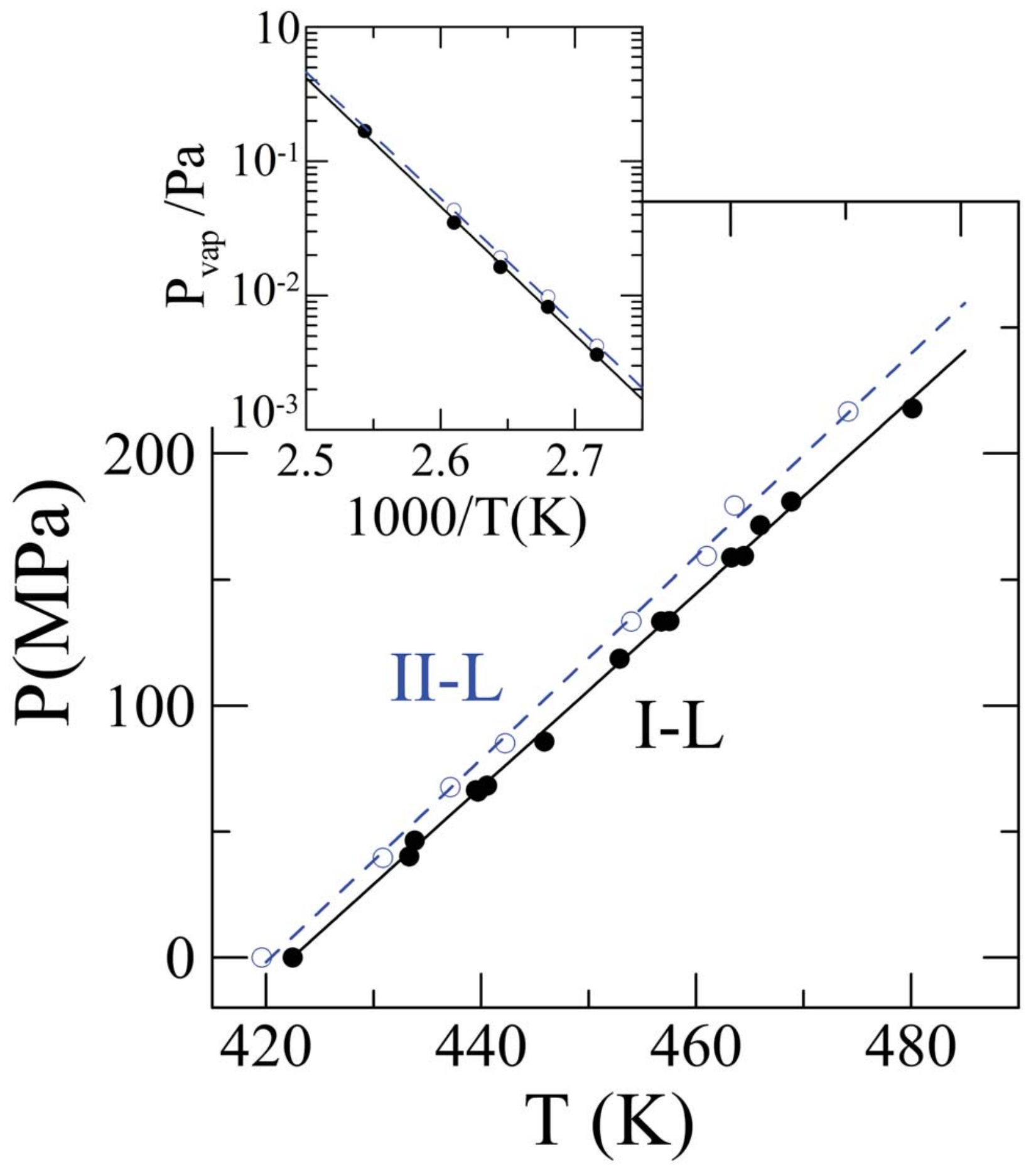




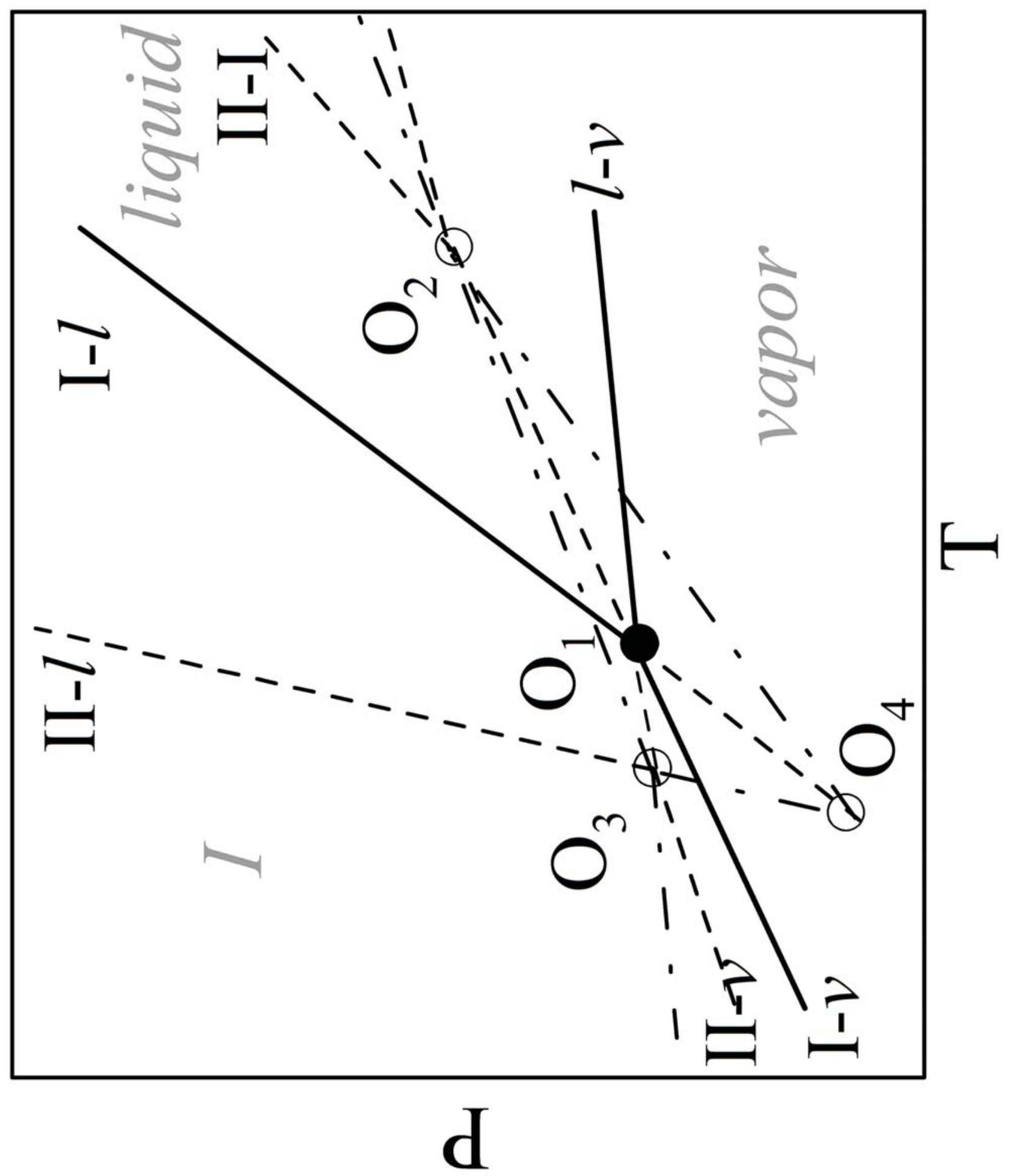


Table 2. Calorimetric data for the two known polymorphs of nimesulide

\begin{tabular}{lllll}
\hline \multicolumn{2}{c}{ Form I } & \multicolumn{2}{c}{ Form II } & Reference \\
\hline $\mathrm{T}_{\text {fus }}($ onset $) / \mathrm{K}$ & $\Delta_{\text {fus }} \mathrm{H} / \mathrm{J} \mathrm{g}^{-1}$ & $\mathrm{~T}_{\text {fus }}($ onset $) / \mathrm{K}$ & $\Delta_{\text {fus }} \mathrm{H} / \mathrm{J} \mathrm{g} \mathrm{g}^{-1}$ & \\
\hline $421.6^{\mathrm{a}}$ & 107.63 & $419.5^{\mathrm{a}}$ & 105.97 & 3 \\
\hline $420.65^{\mathrm{b}}$ & - & $418.95^{\mathrm{b}}$ & - & 4 \\
\hline 422.35 & 121.1 & 420.5 & - & 2 \\
\hline 417.73 & 105.87 & 413.85 & $86.73^{\mathrm{c}}$ & \\
\hline $422.4 \pm 1.0$ & $117.5 \pm 5.2$ & $419.8 \pm 1.0$ & $108.6 \pm 3.3$ & This work $^{\mathrm{d}}$ \\
\hline
\end{tabular}

a DSC heating rate $3 \mathrm{~K} \mathrm{~min}^{-1}$

${ }^{\mathrm{b}}$ DSC heating rate $0.5 \mathrm{~K} \mathrm{~min}^{-1}$

${ }^{\mathrm{c}}$ value obtained by summing the enthalpies of a complex melting process including a broad peak with an enthalpy of $1.58 \mathrm{~kJ} \mathrm{~mol}^{-1}$ preceding a larger peak with an enthalpy of $25.16 \mathrm{~kJ} \mathrm{~mol}^{-1}$.

${ }^{\mathrm{d}}$ Form I mean over 12 measurements, form II mean over 10 measurements 
Table 1. Single crystal data of form I and form II of nimesulide ${ }^{2}$

\begin{tabular}{lccc}
\hline & form $^{\mathbf{a}}$ & ${\text { form } \mathbf{I I}^{\mathbf{b}}}$ & form II $^{\mathbf{c}}$ \\
\hline System & Orthorhombic & Monoclinic & Monoclinic \\
\hline Space group $/ \mathrm{Z}$ & $P c a 2_{1} / 8$ & $\mathrm{C} 2 / \mathrm{c} / 8$ & $\mathrm{C} 2 / \mathrm{c} / 8$ \\
\hline $\mathrm{T} / \mathrm{K}$ & $100(2)$ & $100(2)$ & $293(2)$ \\
\hline$a / \AA$ & $16.1268(19)$ & $33.231(2)$ & $33.657(3)$ \\
\hline$b / \AA$ & $5.0411(6)$ & $5.0720(4)$ & $5.1305(3)$ \\
\hline$c / \AA$ & $32.761(4)$ & $15.8736(12)$ & $16.0816(10)$ \\
\hline$\beta / /^{\circ}$ & 90 & $92.712(2)$ & $92.368(8)$ \\
\hline$V / \AA^{3}$ & $2663.4(5)$ & 2672.46 & $2774.5(3)$ \\
\hline$D_{\text {calc }} / \mathrm{g} \mathrm{cm}^{-3}$ & 1.538 & 1.533 & 1.476 \\
\hline$v / \mathrm{cm}^{3} \mathrm{~g}^{-1}$ & 0.6502 & 0.6523 & 0.6775 \\
\hline$R_{1}[I>2 \sigma(I)]$ & 0.0654 & 0.0341 & 0.0401
\end{tabular}

\begin{tabular}{llll}
\hline Diffractometer & CCD-CAD-4 & CCD-CAD-4 & AED four circle
\end{tabular}

${ }^{\text {a }}$ Reference for the CIF of form I in the Cambridge Structural Database (CSD):

WINWUL01

${ }^{\mathrm{b}} \mathrm{CSD}$ reference for the CIF: WINWUL02

${ }^{c}$ CSD reference for the CIF: WINWUL 